\title{
Optical coherence tomography features and risk of macular hole formation in the fellow eye
}

Birger Lindtjørn ${ }^{1,2^{*}}\left(\mathbb{0}\right.$, Jørgen Krohn $n^{2,3}$ and Vegard A. Forsaa ${ }^{1,4}$

\begin{abstract}
Background: To investigate the risk of primary macular hole $(\mathrm{MH})$ in the fellow eye, and to evaluate baseline characteristics and optical coherence tomography (OCT) features that precede $\mathrm{MH}$ formation in the fellow eye.

Methods: A retrospective review of 229 patients treated for primary MH at Stavanger University Hospital, Norway, from January 2008 through December 2018. The patients were categorised into two groups according to subsequent development of $\mathrm{MH}$ in the fellow eye. The OCT findings of the two groups were compared, and associated risk factors for MH formation assessed.

Results: Twenty cases of bilateral MH were identified. The overall bilateral disease risk was $8.8 \%$ ( $95 \% \mathrm{Cl}, 5.8-13.2 \%)$. Two patients were previously operated in the fellow eye, six patients presented with bilateral $\mathrm{MH}$, and 12 patients subsequently developed $\mathrm{MH}$ in the fellow eye. The risk of subsequent $\mathrm{MH}$ development was $5.7 \%(95 \% \mathrm{Cl}, 3.3-9.8 \%)$. Although the extent of posterior vitreous detachment (PVD) tended to be more progressed in the bilateral group compared with the unilateral group, the difference was not statistically significant. In the bilateral group, $41.7 \%$ had outer retinal defects vs $6.6 \%$ in the unilateral group ( $p=0.001$ ), and $33.3 \%$ in the bilateral group had intraretinal pseudocysts vs $10.2 \%$ in the unilateral group ( $p=0.036$, not significant after multiple testing correction).
\end{abstract}

Conclusion: Outer retinal defects and intraretinal pseudocysts are associated with an increased risk of MH formation in the fellow eye, and complete PVD indicates a decreased risk of MH formation.

Keywords: Bilateral macular holes - epidemiology - macular hole - optical coherence tomography - risk factors vitreoretinal surgery

\section{Background}

The incidence of primary full-thickness macular hole $(\mathrm{MH})$ is $7.9-8.7$ eyes per 100,000 population per year [1, 2]. $\mathrm{MH}$ predominately occur in the elderly population with a male-to-female ratio around 1:3 [2]. A small percentage of $\mathrm{MHs}$ close spontaneously, varying between 4.0 and $11.5 \%$ [3]. If left untreated, the $\mathrm{MH}$ size increases

*Correspondence: birgerl@gmail.com

1 Department of Ophthalmology, Stavanger University Hospital, box 8100, N-4068 Stavanger, PO, Norway

Full list of author information is available at the end of the article over time and severely reduces the visual acuity (VA) to less than 20/200 in the majority of cases $[4,5]$.

The pathogenesis of $\mathrm{MH}$ formation is not yet fully understood. However, it is generally accepted that anteroposterior traction at the vitreoretinal interface is a major contributor to the development of $\mathrm{MH}$ [6]. Previous studies on the risk of bilateral $\mathrm{MH}$ have estimated the risk to be between 7.0 and $16.7 \%$ [1, 2, 4, 7-10]. The use of spectral domain optical coherence tomography (SDOCT) and swept source optical coherence tomography (SS-OCT) enables detection of subtle retinal abnormalities. Some studies have investigated changes at the vitreoretinal interface and showed that foveal or complete original author(s) and the source, provide a link to the Creative Commons licence, and indicate if changes were made. The images or other third party material in this article are included in the article's Creative Commons licence, unless indicated otherwise in a credit line to the material. If material is not included in the article's Creative Commons licence and your intended use is not permitted by statutory regulation or exceeds the permitted use, you will need to obtain permission directly from the copyright holder. To view a copy of this licence, visit http://creativecommons.org/licenses/by/4.0/. The Creative Commons Public Domain Dedication waiver (http://creativeco mmons.org/publicdomain/zero/1.0/) applies to the data made available in this article, unless otherwise stated in a credit line to the data. 
posterior vitreous detachment (PVD) indicates a low risk of $\mathrm{MH}$ formation [7, 11-13]. Studies on retinal abnormalities in fellow eyes have revealed certain structural changes that are associated with an increased risk of $\mathrm{MH}$ formation $[7,11,14,15]$.

Patients with $\mathrm{MH}$ often ask for information about the risk of developing $\mathrm{MH}$ in their fellow eye, and selected patients with a predicted high risk may require regular follow-up examinations and early surgical intervention. This present study sought to provide some answers to these questions based on the evaluation of retinal morphological changes in the fellow eye of patients with $\mathrm{MH}$. The aims of the study were to determine the risk of developing bilateral $\mathrm{MH}$, and to investigate OCT-based vitreoretinal interface- and intraretinal abnormalities associated with $\mathrm{MH}$ formation.

\section{Methods}

\section{Study design and participants}

This retrospective, observational study was conducted at the Department of Ophthalmology at Stavanger University Hospital in Norway. Stavanger University Hospital is the only referral hospital for vitreoretinal surgery in Rogaland County and serves a population of approximately 450,000 inhabitants. As some residents in the northern part of the county may be referred elsewhere, we only included patients living in the 18 southern municipalities of Rogaland County. The medical records of 276 patients who underwent surgery for MH from January 2008 through December 2018 were reviewed. Inclusion criteria were primary $\mathrm{MH}$ with available OCT scans of the fellow eye from the time of primary MH diagnosis or surgery. One patient declined study participation and 46 patients were classified as having secondary $\mathrm{MH}$. We categorised the patients into two groups: A bilateral group comprising subjects who subsequently developed $\mathrm{MH}$ in the fellow eye, and a unilateral group with subjects who did not develop $\mathrm{MH}$ in the fellow eye during follow-up. Macular OCT imaging was performed at the initial visit and the OCT features of the fellow eye in the two groups were compared.

The study was approved by the Regional Committee for Medical and Health Research Ethics (2018/954 REC west, Norway) and followed the tenets of the Declaration of Helsinki. Written informed consent was sent to all living patients, and the opportunity to decline study participation was offered.

\section{Background parameters and optical coherence tomography imaging}

The following patient characteristics were retrieved from the electronic medical records: sex, date of birth, duration of symptoms, laterality, VA in $\operatorname{logMAR}$, date of surgery, and date of death if deceased.

High-resolution OCT images were obtained using SD-OCT or SS-OCT (Topcon 3D OCT 2000 and Topcon DRI OCT Triton; Topcon Corp., Tokyo, Japan) of both eyes when the patient was examined for $\mathrm{MH}$ in the first eye. The scanning protocol used for SD-OCT was a macula $3 \mathrm{D}$ scan, $512 \times 128(6 \times 6 \mathrm{~mm}$, spacing $47 \mu \mathrm{m})$ centred on the macula, and for the SS-OCT a macula 3D scan, $512 \times 256(7 \times 7 \mathrm{~mm}$, spacing $23 \mu \mathrm{m})$ centred on the macula. The vitreomacular interface of the fellow eye was investigated and the PVD status categorised into the following stages:

I) No PVD: no signs of PVD; the posterior vitreous cortex attached to the retinal surface.

II) Perifoveal PVD: the posterior vitreous cortex attached to the fovea, but detached from the retinal surface around the fovea.

III) Foveal PVD: the posterior vitreous cortex not attached to the fovea, but attached to the optic disc. We classified cases where it was difficult to determine the relationship between the vitreous cortex and the optic disc as foveal PVD.

IV) Complete PVD: the posterior vitreous cortex detached from fovea and the optic disc.

Vitreomacular traction (VMT) was defined as the presence of anatomic distortion of the fovea in combination with perifoveal PVD, as described by Duker et al. [16]. The presence of other retinal abnormalities, such as intraretinal cysts, intraretinal splits, outer retinal defects (ORD), epiretinal membrane (ERM) and foveolar detachment in the central macular region was also registered (Fig. 1). Intraretinal splits were defined as tiny horizontal splits within the foveal region, and intraretinal cysts were defined as round-shaped intraretinal cavities [11, 17].

\section{Statistical analysis}

Continuous data were described by mean and standard deviation (SD) when normally distributed, otherwise by median and range. Categorical data were summarised by numbers and proportions. The chi-square test or Fisher's exact test was used for comparing categorical values. The Student's t-test was used to compare normally distributed continuous data, such as age. We used the Wilcoxon signed-rank test to compare related samples. The Wilson score interval was used for estimating binomial proportion confidence intervals (CI). To control the false discovery rate at 0.05 , we applied the Benjamini-Hochberg procedure. The statistical analyses and graphics were made using R Project for Statistical Computing, version 4.0.2 (R Foundation for Statistical Computing, Vienna, 


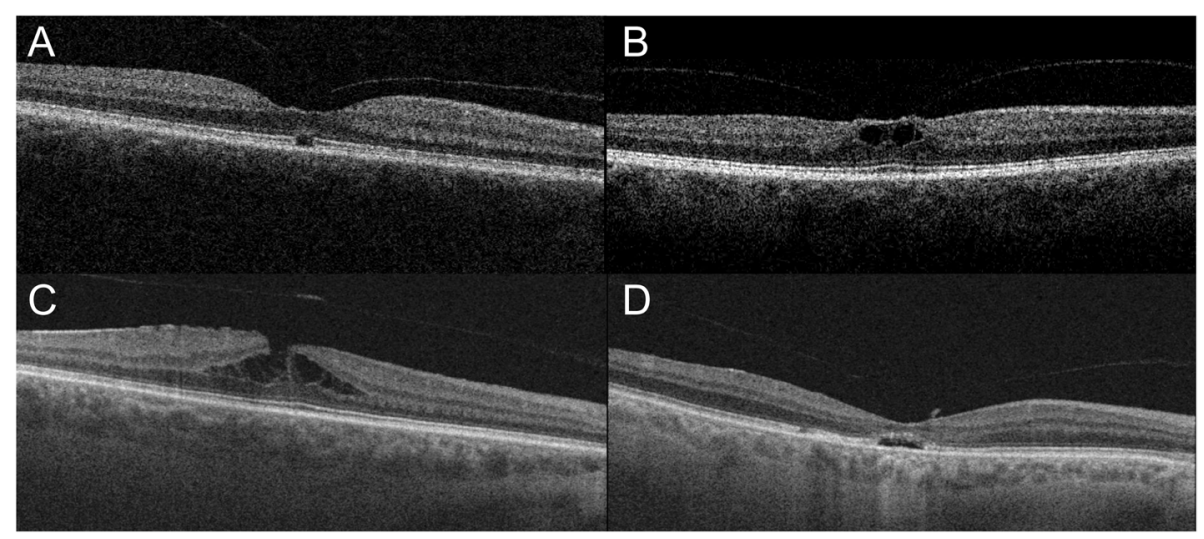

Fig. 1 Optical coherence tomography scans illustrating intraretinal abnormalities we were looking for. A Outer retinal defect. B Intraretinal pseudocysts. C Intraretinal splits. D Foveolar detachment

Austria). Two-tailed $p$-values $\leq 0.05$ were considered statistically significant.

\section{Results}

\section{Participants}

Between January 2008 and December 2018, 229 patients underwent surgery for primary $\mathrm{MH}$. Twenty patients were identified with bilateral disease. Six of the patients presented with bilateral $\mathrm{MH}$, of whom two had an old $\mathrm{MH}$ in the fellow eye unsuitable for surgery. Two patients had been operated for a $\mathrm{MH}$ in their fellow eye prior to 2008. A total of 12 patients subsequently developed a $\mathrm{MH}$ in their fellow eye and were enrolled in the bilateral group. Among the 209 patients with unilateral MH, 9 patients did not have an OCT image of their fellow eye at the initial examination and one patient was excluded due to poor OCT image quality. One patient was excluded due to a prosthesis in the fellow orbit, and one because of previous vitrectomy in the fellow eye. Hence, 197 patients were enrolled in the unilateral group. When calculating the overall risk of bilateral disease, we excluded the two patients with previous surgery in the fellow eye. The mean age at time of operation was $70.6 \pm 8$.6years in the unilateral group and $71.7 \pm 4.8$ years in the bilateral group ( $p=0.50$, Student's t-test). The male-to-female ratio in the bilateral group was 1:5 and 1:1.9 in the unilateral group ( $p=0.35$, Fisher's exact test). Twenty patients presented with a history of $\mathrm{MH}$ or subsequently developed a $\mathrm{MH}$ in the fellow eye. Hence, the overall risk of bilaterality was $8.8 \%$ (95\% CI, 5.8-13.2\%). The risk of subsequent $\mathrm{MH}$ development was 5.7\% (95\% CI, 3.3-9.8\%). Figure 2 illustrates the cumulative frequency of bilateral $\mathrm{MH}$. The median observational time was 54 months (range, 3-138 months). In the bilateral group, the median time interval between the diagnosis of the first and the second
$\mathrm{MH}$ was 17 months (range, 5-83 months), and $75 \%$ of the patients developed the $\mathrm{MH}$ in their fellow eye within 32 months. Two of the 12 patients in the bilateral group and 31 of the 197 patients in the unilateral group were pseudophakic in the fellow eye at baseline $(p=1.0$, Fisher's exact test). In the period until $\mathrm{MH}$ development in the fellow eye, two patients in the bilateral group underwent cataract surgery. Consequently, 8 of the 12 patients in the bilateral group were phakic at the time of $\mathrm{MH}$ formation in the relevant eye. Table 1 summarises the baseline demographics and OCT features of the two groups.

\section{Optical coherence tomography findings}

Foveal PVD in the fellow eye occurred in three patients (25\%) in the bilateral group and in 74 patients $(37.6 \%)$ in the unilateral group $(p=0.35)$. Figure 3 demonstrates the development of $\mathrm{MH}$ in a patient with foveal PVD. None of the patients in the bilateral group had a complete PVD compared to 23 patients $(11.7 \%)$ in the unilateral group $(p=0.35)$. Although not significant, the extent of the PVD in the fellow eye seemed to be more advanced in the unilateral group compared to the bilateral group. The presence of VMT and ERM in the fellow eye was not significantly different between the two groups.

Outer retinal defects were present in $41.7 \%$ of the fellow eyes in the bilateral group and in only $6.6 \%$ of the fellow eyes in the unilateral group $(p=0.001)$. The presence of ORD had a sensitivity of $41.7 \%$ (95\% CI, 19.3-68.0\%) and specificity of $93.4 \%$ (95\% CI, 89.0-96.1\%) in detecting subsequent $\mathrm{MH}$ formation. The presence of pseudocysts was also higher in the bilateral group with $33.3 \%$ compared to $10.2 \%$ in the unilateral group $(p=0.036)$, but did not remain statistically significant after correction for multiple testing. There were no statistically significant differences regarding the presence of intraretinal 


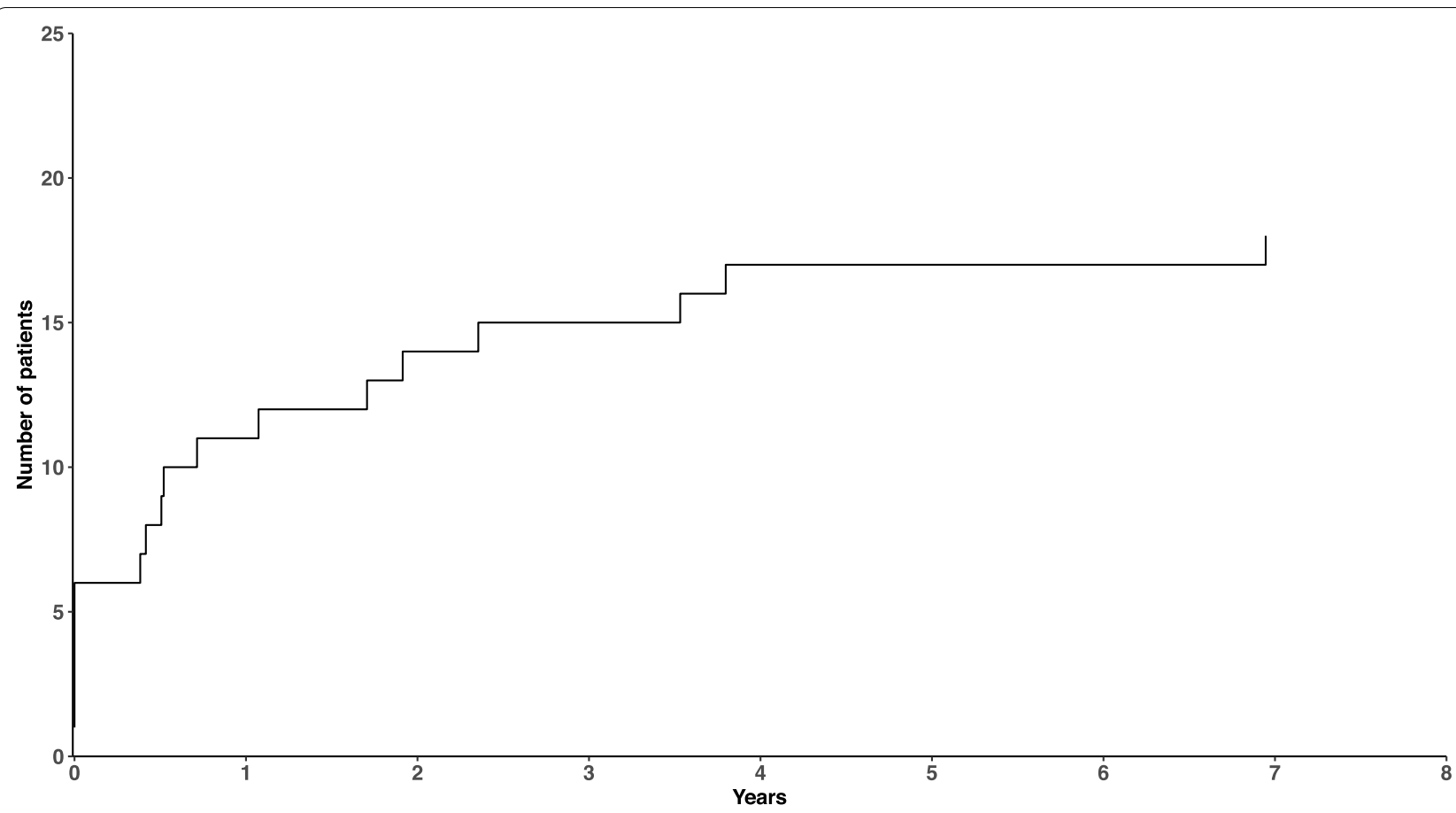

Fig. 2 Cumulative frequency curve of macular hole in the fellow eye after diagnosis of macular hole in the first eye. Six patients who presented with bilateral macular hole at the initial visit were included

Table 1 Baseline demographics and optical coherence tomography features of the fellow eye

\begin{tabular}{|c|c|c|c|}
\hline & $\begin{array}{l}\text { Bilateral } \\
\text { group }(n= \\
12)\end{array}$ & $\begin{array}{l}\text { Unilateral } \\
\text { group }(n= \\
197)\end{array}$ & $P$ \\
\hline Age, mean (SD), years & $71.7(4.8)$ & $70.6(8.6)$ & $0.509^{*}$ \\
\hline Sex, male/female & $2 / 10$ & $68 / 129$ & $0.345^{+}$ \\
\hline Pseudophakia, $n(\%)$ & $2(16.7)$ & $31(15.7)$ & $1.0^{\dagger}$ \\
\hline $\begin{array}{l}\text { Interval between both eyes, } \\
\text { median (range), months }\end{array}$ & $17(5-83)$ & NA & \\
\hline \multicolumn{4}{|l|}{ Vitreoretinal relationship, n (\%) } \\
\hline No PVD & $2(16.7)$ & $19(9.6)$ & $0.352^{+}$ \\
\hline Perifoveal PVD & $7(58.3)$ & $81(41.1)$ & \\
\hline Foveal PVD & $3(25.0)$ & $74(37.6)$ & \\
\hline Complete PVD & 0 & $23(11.7)$ & \\
\hline \multicolumn{4}{|l|}{ Retinal abnormalities, $n(\%)$} \\
\hline VMT & $3(25.0)$ & $33(16.8)$ & $0.438^{+}$ \\
\hline Epiretinal membrane & $4(33.3)$ & $50(25.4)$ & $0.512^{\dagger}$ \\
\hline Outer retinal defects & $5(41.7)$ & $13(6.6)$ & $0.001^{\dagger}$ \\
\hline Intraretinal splits & $4(33.3)$ & $27(13.7)$ & $0.083^{\dagger}$ \\
\hline Pseudocysts & $4(33.3)$ & $20(10.2)$ & $0.036^{\dagger}$ \\
\hline Foveolar detachment & 0 & $6(3.0)$ & $1.0^{\dagger}$ \\
\hline
\end{tabular}

MH Macular hole, NA Not applicable, PVD Posterior vitreous detachment, SD Standard deviation, VMTVitreomacular traction

* Students t-test.

${ }^{\dagger}$ Fisher's exact test.

$p$-values that remain statistically significant after applying the BenjaminiHochberg procedure for multiple testing are presented in bold. splits and foveolar detachment. All three patients in the bilateral group with foveal PVD in the fellow eye displayed ERM, ORD and a visible pseudo-operculum in the same eye. Among the patients with ORD in the fellow eye, $27.8 \%$ (95\% CI, $12.5-50.9 \%)$ subsequently developed a $\mathrm{MH}$. The presence of ORD was the strongest predictor of $\mathrm{MH}$ development in the fellow eye (Fig. 4). Table 2 shows a comparison of VA, MH diameter and duration of symptoms between the first and the second eye, for which no significant differences were found.

\section{Discussion}

In this study, we found an overall risk of bilateral $\mathrm{MH}$ of $8.8 \%$, illustrating a profoundly higher probability of $\mathrm{MH}$ in the fellow eye compared to the risk of first eye $\mathrm{MH}$ in the general population $[1,2]$. The risk of subsequent $\mathrm{MH}$ formation was $5.7 \%$. These results are in accordance with those of McCannel et al., Furashova \& Matthè, and Lewis et al. [2, 4, 18]. Other studies however, have reported a higher risk of bilateral $\mathrm{MH}$ formation [7, 8]. Ezra et al. reported a bilateral risk of $15.6 \%$, but their study was based on a subgroup of fellow eyes without PVD, which may have caused overestimation of the overall risk of bilateral MH formation [9]. Ali et al. reported that AsianAmericans had a 177\% increased risk of $\mathrm{MH}$ formation compared to Caucasians [19]. Ethnic susceptibility to $\mathrm{MH}$ formation may partly explain why Kumagai et al. and 


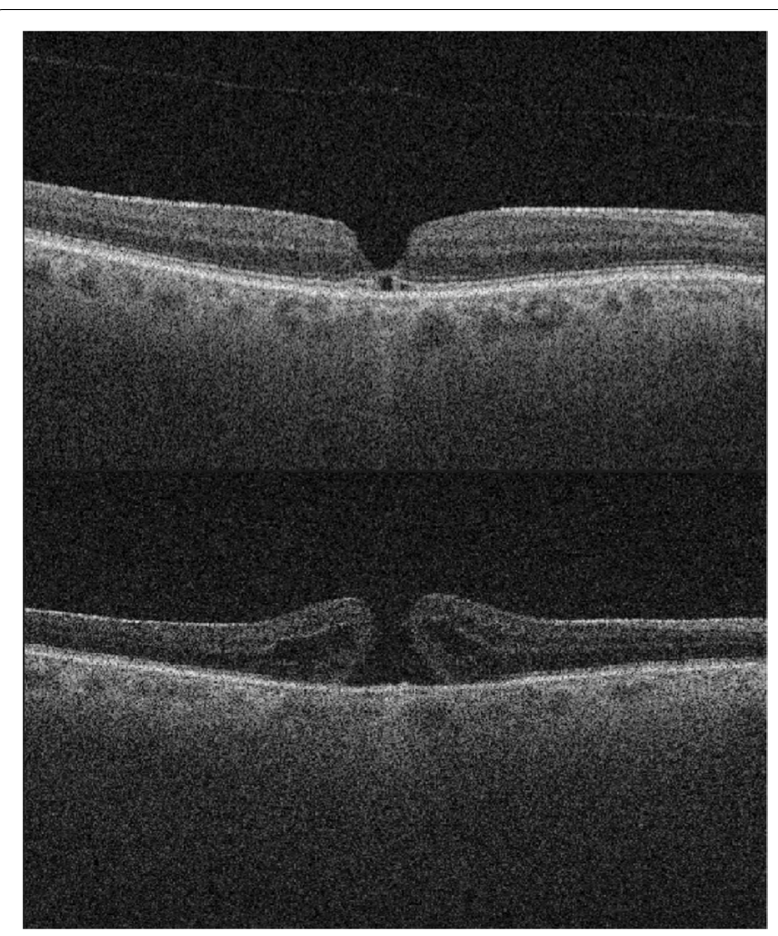

Fig. 3 The upper image shows an optical coherence tomography scan of the fellow eye of a patient with macular hole at the initial visit. Outer retinal defects, foveal posterior vitreous detachment and a thin epiretinal membrane are present. The lower image, captured four months later, shows that the patient has developed a full-thickness macular hole

Choi et al. reported a higher risk of bilateral $\mathrm{MH}$ formation $[7,8]$. Our calculated risk may be underestimated as individuals in the unilateral group may develop a $\mathrm{MH}$ in the fellow eye after ended data collection. Our study relied on the high probability of patients developing a $\mathrm{MH}$ in their fellow eye being readmitted to the Stavanger University Hospital. Still, we cannot fully exclude the risk that some patients have moved out of our catchment area or been referred elsewhere with a $\mathrm{MH}$ in the fellow eye. We did not investigate the family history of $\mathrm{MH}$ in our patients. Kay et al. reported a significantly higher frequency of $\mathrm{MH}$ among family members of patients with bilateral MHs, which may indicate a genetic predisposition in some individuals [20].

Although not statistically significant, PVD had reached a more progressed stage in the unilateral group, and no fellow eye with complete PVD developed fullthickness MH. Several studies have demonstrated that complete PVD is negatively associated with the development of MH $[7,18]$. Surprisingly, three eyes with foveal PVD subsequently progressed to a full-thickness $\mathrm{MH}$. Hence, VMT is not the only contributor to MH development and foveal or complete PVD does not rule out the possibility of $\mathrm{MH}$ formation. However, the presence of ORD and a pseudo-operculum in these three cases indicate previous vitreomacular traction and a weakened foveal structure. In a study by Takahashi et al., five out of 16 patients with foveal PVD subsequently developed a MH [11]. Besirli \& Johnson described two cases with foveal PVD who developed $\mathrm{MH}$, where OCT imaging revealed foveal contour irregularities consistent with previous vitreomacular traction [21]. Peeling of the internal limiting membrane improves the closure rates after $\mathrm{MH}$ surgery, which indicates the presence of tangential traction forces on the retinal surface [22]. In a prospective study on 34 individuals with lamellar $\mathrm{MH}$, Bottoni et al. detected two patients with PVD and concomitant ERM who subsequently developed fullthickness MH [23]. A post hoc evaluation of the three patients with foveal PVD and MH formation in our study revealed that two of the cases had a thick ERM and one had a thin ERM. Recently, Bringmann et al. described different modes of $\mathrm{MH}$ formation and emphasised that $\mathrm{MH}$ formation is caused by disruption of both Müller cell cones and the external limiting membrane [24]. A plausible theory explaining our three cases with foveal PVD and MH formation, is that initially, vitreomacular traction caused structural damage to the fovea. Subsequently, this vulnerability facilitated the formation of a full-thickness $\mathrm{MH}$ induced by tangential traction by the ERM on the retinal surface.

Outer retinal defects were significantly more frequent in the bilateral group. In accordance with Choi et al., we found the presence of ORD to have the highest positive predictive value of developing $\mathrm{MH}$, with a sensitivity of $41.7 \%$ in predicting $\mathrm{MH}$ formation [7]. However, while Choi et al. reported a specificity of $100 \%$, we found it to be $93.4 \%$. In our study, five out of 18 patients with ORD developed a MH. In contrast, all five eyes with ORD in the study by Choi et al. developed a MH. Nevertheless, many of our patients in the unilateral group had retinal abnormalities in the fellow eye. This is in accordance with the findings of Chhablani et al. and Kumagai et al., reporting that retinal abnormalities and vitreofoveal interface changes are more common in fellow eyes of patients with $\mathrm{MH}$ than in a matched healthy population $[15,25]$.

In the bilateral group, we found no significant differences between the first and the second eye regarding preoperative VA, MH size or duration of symptoms. One would expect that patients would seek medical assistance at an earlier stage when suffering from a $\mathrm{MH}$ in their fellow eye. In Norway, patients need a referral from a health care professional to access specialised hospital departments, which may explain some of the delay from onset of symptoms to treatment. 

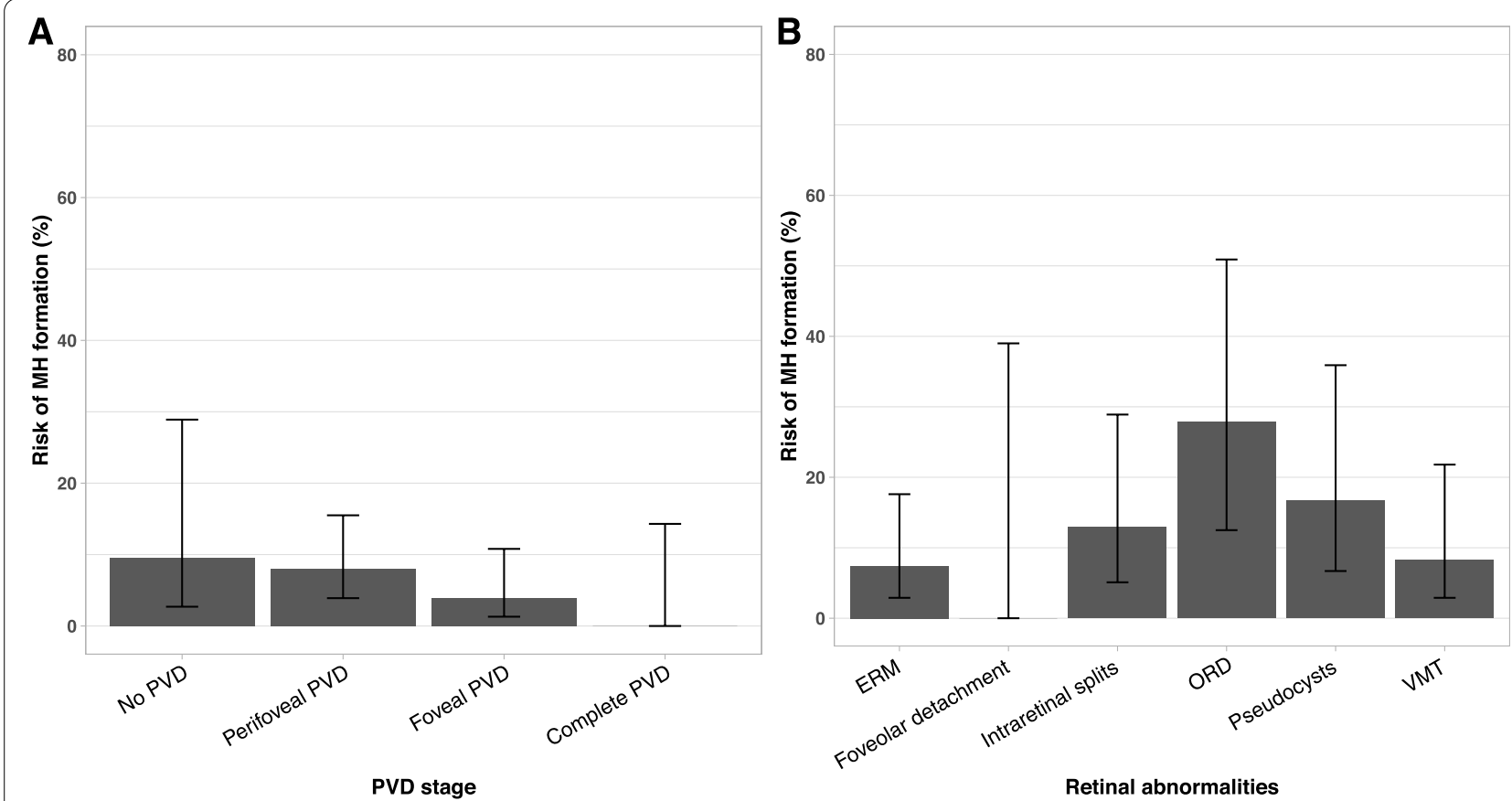

Fig. 4 Bar graph illustrating the risk of subsequent MH formation in the fellow eye depending on A PVD stage and $\mathbf{B}$ the presence of retinal abnormalities. $\mathrm{ERM}=$ epiretinal membrane; $\mathrm{MH}=$ macular hole; $\mathrm{PVD}=$ posterior vitreous detachment; $\mathrm{ORD}=$ outer retinal defects; VMT $=$ vitreomacular traction

Table 2 Comparison of first and second eye in the bilateral group

\begin{tabular}{llll}
\hline & First eye & Second eye & $P$ \\
\hline Preoperative VA, mean (SD), logMAR & $0.63(0.14)(n=10)$ & $0.63(0.19)(n=12)$ & $388(169)(n=12)$ \\
MH diameter, mean (SD), $\mu \mathrm{m}$ & $356(177)(n=12)$ & $4(1-12)(n=12)$ & $0.81^{*}$ \\
Duration of symptoms, median (range), months & $5(1-8)(n=10)$ & $0.52^{*}$ \\
\hline
\end{tabular}

MH Macular hole, SD Standard deviation, VA Visual acuity

* Wilcoxon signed-rank test

The present study has several limitations including its retrospective design and a relatively small sample size. We only examined the OCT images of the fellow eye captured at the time when the first eye was examined for a MH. A longitudinal study design with repeated OCT examinations could have revealed other transient retinal abnormalities and vitreoretinal interface changes. OCT images were available for $94 \%$ of the fellow eyes in the unilateral group and for all of the fellow eyes that subsequently developed MH. Due to the retrospective study design, two different OCT systems, SS-OCT and SD-OCT, were used in the study. SS-OCT provides narrower spacing and better detection of deeper signals, posterior to the retinal pigment epithelium (RPE). However, both SS-OCT and SD-OCT use the Fourier domain detection techniques and allow detection of subtle retinal changes anterior to the RPE [26].

\section{Conclusion}

Our study provides useful information when counselling patients with $\mathrm{MH}$. This patient group has a substantially increased risk of developing a $\mathrm{MH}$ in the fellow eye compared to the general population. The presence of complete PVD indicates a minimal risk of developing a $\mathrm{MH}$, while the presence of ORD reveals a significantly higher risk of $\mathrm{MH}$ formation.

\section{Abbreviations}

Cl: Confidence interval; ERM: Epiretinal membrane; MH: Macular hole; OCT: Optical coherence tomography; ORD: Outer retinal defects; PVD: Posterior vitreous detachment; RPE: Retinal pigment epithelium; SD: Standard deviation; SD-OCT: Spectral domain optical coherence tomography; SS-OCT: Swept source optical coherence tomography; VA: Visual acuity; VMT:Vitreomacular traction.

\section{Acknowledgements} Not applicable. 


\begin{abstract}
Authors' contributions
$\mathrm{BL}$, JK and VAF contributed to the study conception and design. Measurements, data collection and data analysis were performed by BL. BL wrote the first manuscript draft. BL, JK and VAF contributed in the commenting and editing process of the manuscript. All authors have read and approved the final version of the manuscript.
\end{abstract}

\section{Funding}

This research received no specific grant from any funding agency in the public, commercial, or not-for-profit sectors.

\section{Availability of data and materials}

The dataset is available from the corresponding author on reasonable request.

\section{Declarations}

\section{Ethics approval and consent to participate}

The study was approved by the Regional Committee for Medical and Health Research Ethics (2018/954 REC west, Norway). Passive informed consent was obtained from all living patients included in the study. A letter informing about the study was sent to all living patients who had underwent MH surgery at Stavanger University Hospital from 2008 to 2018. Patients who wished to decline participation, could contact us by letter, e-mail, SMS or phone. The regional ethic committee approved this method of consent. All data were anonymised before use.

\section{Consent for publication}

Not applicable.

\section{Competing interests}

None of the authors have any conflicting interests to disclose.

\begin{abstract}
Author details
${ }^{1}$ Department of Ophthalmology, Stavanger University Hospital, box 8100, N-4068 Stavanger, PO, Norway. ${ }^{2}$ Department of Clinical Medicine, Section of Ophthalmology, University of Bergen, Bergen, Norway. ${ }^{3}$ Department of Ophthalmology, Haukeland University Hospital, Bergen, Norway. ${ }^{4}$ Department of Quality and Health Technology, University of Stavanger, Stavanger, Norway.
\end{abstract}

Received: 9 May 2021 Accepted: 16 September 2021

Published online: 29 September 2021

\section{References}

1. Forsaa VA, Lindtjorn B, Kvaloy JT, Froystein T, Krohn J. Epidemiology and morphology of full-thickness macular holes. Acta Ophthalmol. 2018;96(4):397-404. https://doi.org/10.1111/aos.13618.

2. McCannel CA, Ensminger JL, Diehl NN, Hodge DN. Population-based incidence of macular holes. Ophthalmology. 2009;116(7):1366-9. https://doi.org/10.1016/j.ophtha.2009.01.052

3. Liang X, Liu W. Characteristics and risk factors for spontaneous closure of idiopathic full-thickness macular hole. J Ophthalmol. 2019;2019:4793764. https://doi.org/10.1155/2019/4793764.

4. Lewis ML, Cohen SM, Smiddy WE, Gass JD. Bilaterality of idiopathic macular holes. Graefes Arch Clin Exp Ophthalmol. 1996;234(4):241-5. https://doi.org/10.1007/BF00430416.

5. Berton M, Robins J, Frigo AC, Wong R. Rate of progression of idiopathic full-thickness macular holes before surgery. Eye (Lond). 2020;34(8):138691. https://doi.org/10.1038/s41433-019-0654-1.

6. Steel DH, Lotery AJ. Idiopathic vitreomacular traction and macular hole: a comprehensive review of pathophysiology, diagnosis, and treatment. Eye (Lond). 2013;27(Suppl 1):S1-21. https://doi.org/10.1038/eye.2013.212.

7. Choi JH, Kim KT, Kang SW, Bae K, Lee SE, Kim AY. Development of idiopathic macular hole in fellow eyes: spectral domain optical coherence tomography features. Retina. 2020;40(4):765-72. https://doi.org/ 10.1097/IAE.0000000000002439.

8. Kumagai K, Ogino N, Hangai M, Larson E. Percentage of fellow eyes that develop full-thickness macular hole in patients with unilateral macular hole. Arch Ophthalmol. 2012;130(3):393-4. https://doi.org/10. 1001/archopthalmol.2011.1427.
9. Ezra E, Wells JA, Gray RH, Kinsella FM, Orr GM, Grego J, et al. Incidence of idiopathic full-thickness macular holes in fellow eyes. A 5-year prospective natural history study. Ophthalmology. 1998;105(2):353-9. https://doi.org/10.1016/s0161-6420(98)93562-X.

10. Niwa H, Terasaki H, Ito Y, Miyake Y. Macular hole development in fellow eyes of patients with unilateral macular hole. Am J Ophthalmol. 2005;140(3):370-5. https://doi.org/10.1016/j.ajo.2005.03.070.

11. Takahashi A, Yoshida A, Nagaoka T, Kagokawa H, Kato Y, Takamiya A, et al. Macular hole formation in fellow eyes with a perifoveal posterior vitreous detachment of patients with a unilateral macular hole. Am J Ophthalmol. 2011;151(6):981-9.e4. https://doi.org/10.1016/j.ajo.2011.01.011.

12. Fisher YL, Slakter JS, Yannuzzi LA, Guyer DR. A prospective natural history study and kinetic ultrasound evaluation of idiopathic macular holes. Ophthalmology. 1994;101(1):5-11. https://doi.org/10.1016/s0161-6420(94)31356-x.

13. Trempe CL, Weiter JJ, Furukawa H. Fellow eyes in cases of macular hole. Biomicroscopic study of the vitreous. Arch Ophthalmol. 1986;104(1):935. https://doi.org/10.1001/archopht.1986.01050130103031.

14. Michalewska Z, Michalewski J, Sikorski BL, Kałuzny JJ, Wojtkowski M, Adelman RA, et al. A study of macular hole formation by serial spectral optical coherence tomography. Clin Exp Ophthalmol. 2009;37(4):37383. https://doi.org/10.1111/j.1442-9071.2009.02041.x.

15. Chhablani J, Kumar K, Ali TR, Narayanan R. Spectral-domain optical coherence tomography features in fellow eyes of patients with idiopathic macular hole. Eur J Ophthalmol. 2014;24(3):382-6. https://doi.org/10.5301/ejo.5000386.

16. Duker JS, Kaiser PK, Binder S, de Smet MD, Gaudric A, Reichel E, et al. The international Vitreomacular traction study group classification of vitreomacular adhesion, traction, and macular hole. Ophthalmology. 2013;120(12):2611-9. https://doi.org/10.1016/j.ophtha.2013.07.042.

17. Haouchine B, Massin P, Gaudric A. Foveal pseudocyst as the first step in macular hole formation: a prospective study by optical coherence tomography. Ophthalmology. 2001;108(1):15-22. https://doi.org/10. 1016/s0161-6420(00)00519-4

18. Furashova O, Matthe E. Foveal crack sign as a predictive biomarker for development of macular hole in fellow eyes of patients with full-thickness macular holes. Sci Rep. 2020;10(1):19932. https://doi.org/10.1038/s41598-020-77078-y.

19. Ali FS, Stein JD, Blachley TS, Ackley S, Stewart JM. Incidence of and risk factors for developing idiopathic macular hole among a diverse Group of Patients throughout the United States. JAMA Ophthalmol. 2017;135(4):299-305. https://doi.org/10.1001/jamaophthalmol.2016.5870.

20. Kay CN, Pavan PR, Small LB, Zhang T, Zamba GK, Cohen SM. Familial trends in a population with macular holes. Retina. 2012;32(4):754-9. https://doi.org/10.1097//AE.0b013e3182252a92.

21. Besirli CG, Johnson MW. Traction-induced foveal damage predisposes eyes with pre-existing posterior vitreous detachment to idiopathic macular hole formation. Eye (Lond). 2012;26(6):792-5. https://doi.org/10.1038/eye.2012.21.

22. Chatziralli IP, Theodossiadis PG, Steel DHW. Internal limiting membrane peeling in macular hole surgery; why, when, and how? Retina. 2018;38(5):870-82. https://doi.org/10.1097/IAE.0000000000001959.

23. Bottoni F, Deiro AP, Giani A, Orini C, Cigada M, Staurenghi G. The natural history of lamellar macular holes: a spectral domain optical coherence tomography study. Graefes Arch Clin Exp Ophthalmol. 2013;251(2):467-75. https://doi.org/10.1007/s00417-012-2044-2.

24. Bringmann A, Unterlauft JD, Barth T, Wiedemann R, Rehak M, Wiedemann P. Different modes of full-thickness macular hole formation. Exp Eye Res. 2021;202:108393. https://doi.org/10.1016/j.exer.2020.108393.

25. Kumagai K, Hangai M, Larson E, Ogino N. Vitreoretinal interface and foveal deformation in asymptomatic fellow eyes of patients with unilateral macular holes. Ophthalmology. 2011;118(8):1638-44. https:// doi.org/10.1016/j.ophtha.2011.01.022.

26. Miller AR, Roisman L, Zhang Q, Zheng F. Rafael de Oliveira Dias J, Yehoshua $Z$ et al: comparison between spectral-domain and swept-source optical coherence tomography angiographic imaging of Choroidal neovascularization. Invest Ophthalmol Vis Sci. 2017;58(3):1499-505. https://doi.org/10.1167/iovs.16-20969.

\section{Publisher's Note}

Springer Nature remains neutral with regard to jurisdictional claims in published maps and institutional affiliations. 